\title{
A Conceptual Model of Listening Effectiveness and Agile Selling Behavior: Moderating Effect of E-Communication and Consumption Pattern
}

\author{
Shahriar Gias* \\ Slippery Rock University, USA
}

*Corresponding author: Shahriar Gias, Associate Professor, Department of Marketing, School of Business Slippery Rock University, USA.

Received Date: December 19, 2019

Published Date: January 03, 2020

\begin{abstract}
This article examines the importance of the salespeople listening effectiveness in relation to sales performance and purchase intention. Subsequently, it also investigates how sales agility, decision making style, e-communication and types of consumption goals moderates the relationship between listening effectiveness and sales performance as well as purchase intention. A total of six hypotheses have been developed for empirical testing purpose. The result shows that salespeople listening skill is crucial for the organization success and gaining competitive advantages over others and indeed it is strongly and positively related to the sales performance and purchase intention. Finally, managerial implication and future research direction have been proposed.
\end{abstract}

Keywords: Sales agility; Hedonic; Utilitarian; Adaptive selling; E-communication

\section{Introduction}

"If speaking is silver, then listening is gold." - Turkish Proverb

Effective communication is paramount in today's complex, fastpaced, and high-intensity organizations. Listening is the foremost effective communication tool that is critical to success in business. Listening itself makes a difference between profit and loss, between success and failure, between a long career and a short one [1]. Clearly, "the value of listener engagement as a communicational ideal is of the highest necessity in our professional lives and for the leaders - executives, managers, supervisors, salespeople and others in highly visible and responsible role" [2]. Business with effective listeners are rewarded not only with more satisfied customers and increased sales but also with more satisfied personnel and increased productivity which in turn leads to increased profits [3]. Listening is one of the six major components of the interactivity dimension, along with responsiveness, didactics, understanding, personalization and psychological proximity [4]. Willingness to listen demonstrates that a person has a certain degree of attentiveness [5]. It is essential for the customer-oriented approach of a salesperson and is positively related to customer satisfaction [6]. The consumer's perception of a salesperson's listening behavior has an impact on the promotion of long-term relationships, building of trust and satisfaction, and anticipation of future interactions [7]. Human interaction has always been a key area of discussion in business environment especially for the organizations which are pre-dominantly sales orientated. Bitner, et al. [8]recognizes the role of the frontline employees since the behavior of contact employees can distinguish a highly satisfactory service encounter from a dissatisfactory service encounter. Previous researches have already found that the average salesperson shows a sign of poor listening skills as well as identified it as number one weaknesses for most sales representatives [9]. Moore, et al. [10] found that salespeople listening effectiveness is more important than identifying customer needs, time management skills and their ability to become close to the customers. Previous research also suggested that sales success is likely related to the salesperson's ability to listen to a customer $[7,11,12]$. Bergeron J [13] mentioned that several bestselling business authors stressed the positive relationship between listening skills and success in business [14-16]. Peters T, et al. [17] define corporate excellence as being "built on bedrock of listening and hence distinguish excellent companies as those that value listening [18]. According to Ramsey RP, et al. [7] classified listening 
to the customer as a major source of selling effectiveness which has been under-researched behavioral phenomenon in the marketing literature.

Even though, few researches have been done in the area of salespeople listening skills and sales performance, those researches are very much limited to the relationship of how listening skills affect the sales performance of the company. Castleburry SB, et al. [19] addressed the need of more study designed to establish the link between effective listening and sales performance. Having understood that the interest of studying listening in the selling environment is growing as well as the current changes in business practice and environment, it is imperative to reestablish that link at the presence of more moderating variables. Therefore, the main purpose of this paper is to analyze the relationship between salespeople listening effectiveness and sales performance as well as purchase intention. Subsequently, it explores how four moderators (agility, e-communication, decision style, type of consumption goals) influence this relationship.

\section{Contribution and incremental knowledge}

None of research on salespeople listening effectiveness have taken into consideration the effect of e-communication and other technological touch points as well as the ever-changing business and selling environmental contexts and organizational/ workforce agility concept. This paper intends to fill out this literature gap by first readdressing the dyadic relationship of salespeople listening effectiveness in regard to purchase intention and sales performance. Secondly, it also examines the moderating effect of consumer decision making style and utilization of e-communication business practice. Finally, research question has been proposed in regard to moderating effect of two types of consumer consumption goals on salespeople listening

effectiveness and sales performance as well as purchase intention. Castleburry SB, et al. [19] demonstrated a relationship between salespeople listening and adaptive selling. Having understood the difference between the adaptive selling and sales agility, this paper is the first that use sales agility in relation to salespeople listening effectiveness. Previous research works only emphasize on the adaptive selling approach but very few researches actually see organization's business practice style from the adaptive business standpoint. Therefore, the analysis of agile workforce as well as salespersons' agility will shed some light in the current sales literature. Sales-people knowledge in technology touch point such as involving in an e-communication method and social media exposure is another key contribution of this paper. It is expected that high use of e-communication method will allow salespeople to engage more in a listening behavior. Also, moderating role of consumer's decision style and consumption goals are some of the new areas that sales literature needs to explore in terms of salespeople listening effectiveness because understating of different consumers decision making styles will allow salespeople to analyze customer needs and wants and hence provide a better customer service.

\section{Literature Review}

\section{Definition and importance of listening}

The construct, listening has been defined by many researchers in a various different way. The very early definition of listening has been provided by Castleburry SB, et al. [19] as "the cognitive process of actively sensing, interpreting, evaluating, and responding to the verbal and nonverbal messages of present or potential customers". Bergeron J, et al. [9] defined listening as a complex cognitive, affective and behavioral activity which is a selective act of physically sensing, mentally processing and responding to verbal and nonverbal messages. Harris [2]define listening as a thinking process and states that it is mental involvement process where people engage in to get information, interpret it, evaluate it and prioritize it. Bernard TF [20] states that listening is the front end of decision making as it provides a most efficient route to judgments.

Caudill, et al. [21] states that a salesperson needs good listening skills in order to identify customer needs and wants properly and hence they should learn to ask the customers right questions. Bitner et al. [22,23] defined frontline employees as a critical source of information about customers. The knowledge they acquired from customers not only help them to interact with customers in a better way but also allow firms to modify the important business decisions. Asking and gathering right questions often start from the effective listening habit. A study published in Wall Street Journal in 1990 [24] provided evidence that $80 \%$ of buyers felt salespeople did not know the right questions to ask and were too talky. Webster Jr, et al. [25] emphasis that sales interactions first identify the prospect's needs and turn them into buying motives [26]. Therefore, he suggests that the salespeople must listen carefully to the prospect's description of problems in order to uncover the prospect's personal and social needs [26]. Comer, et al. [27] found a significant positive result between sales-people effective listening behavior and overall selling process and sales performance.

Bitner et al. [8] showed that customer satisfaction not always necessarily results from providing higher service quality rather it largely depends on how service employee reacts to unanticipated situation such as service failure circumstances. Moreover, higher degree of customer dissatisfaction observed when customers find out that the service worker cannot handle the service failure situation [28]. According to Boshoff C, et al. [29] frontline employees not only play crucial role during the service failure stage but also play an important role in service recovery stage. One study conducted in Bitner et al. [8] paper found out that one hundred percent of the participants recalled the "critical incidents" regardless of good or ill related directly to the salespeople reaction or responsiveness during the transaction in order to evaluate or recall the sales and service transaction [28]. According to Ferrari TF [20] effective listening not only increases individual performance but also shapes the reputation of your organization where that individual works. Listening to the customer shows that salespeople is actually putting efforts to understand and ensure the wellbeing of the customers and hence the salesperson is taking their 
first step towards building a healthy, strong-relationship with that customer [30]. Wolvin AD, et al. [3] states that "the salesperson is the most important communicator in the entire organization, since all other efforts are of no avail if the salespeople are unable to communicate in a manner than induce purchase". Verret [30] states that salespeople can respond more appropriately and reduce selling time by evaluating exactly what the customer is saying and evaluating their own response before speaking. Richard TE [31] suggests that effective salespeople use the information gained by listening to "harmonize" the customers' needs with appropriate products and benefits [32].

\section{Conceptual framework}

The theoretical framework of this paper is based on the process model of listening, adapting, and performance proposed by Castleberry SB, et al. [19] and the adapting selling model proposed by Weitz BA, et al. [33]. Both of those framework states that certain skills of a salesperson are antecedents to the practice of adapting selling which then leads to performance. The proposed framework of this paper makes a clear distinction from other models by proposing sales agility in lieu of adapting selling approach which in turn will lead to both sales' performance and purchase intention.

\section{Proposed Model}

\section{Theory and hypothesis}

Purchase Intention: Marketers have long recognized the benefit of having a long-term loyal customer base. Thomas RW, et al. [34] empirically shows that cost of retaining a long-term existing customer group is less expensive than prospecting for a new customer. Purchase intention refers to "the degree of perceptual conviction of a customer to repurchase a particular product or to repurchase any product at a particular organization" [35].

According to Nugent WR [36], listening creates a positive impact on clients and practitioner-client relationship. A survey done by Ramsey RP, et al. [7] resulted that perceptions of salespeople listening had a significant positive effect on a customer's anticipation of future interaction with the salespeople. When customer perceive that a salesperson is listening to what they are saying, they may feel cared for, understood and more inclined to interact with that salesperson again [7]. Hence, listening skill allows salespeople to do develop a friendly atmosphere with their customers and motivate them to come and buy the product from the same salespeople on the basis of that friendliness. Also, Luce MF [37] claims that the influence of prior customer loyalty is likely to be very strong because customers maintain the status quo to satisfy coping goals, thereby minimizing explicit confrontation of negative potential decision consequences. Therefore, based on these above analyses it is reasonable to believe that

H1: Salesperson listening effectiveness will positively influence consumer's purchase intention. Sales Performance: Salespeople who are effective listeners are the one with good sales performance records [55,2] [38,39]. Accordingly, Wolvin AD, et al. [40] salesperson who first asks the customer about his or her needs and then listens to the customer's verbal responses is better able to determine how a product will meet the customer's needs and eventually increase the sales volume through fulfilling the customer's wants and needs. Shepherd CD, et al. [41] empirical self-reported study found the positive relationship between the salespeople's listening behavior and sales performance (Figure 1). Another study by Boorom ML, et al. [42] surveyed a convenience sample of 239 insurance agents and found a positive association between listening and sales performance. According to Spiro RL, et al. [43] effective interpersonal listening allows the salesperson to gain the accurate perception needed to practice adaptive selling behavior, which in turn should result in higher performance [2] . Also, Castleberry SB, et al. [44] found the positive correlation between three components of listening (sensing, processing, and responding) and sales performance. Based on these research works, it is expected to conclude that:

\section{Proposed Model}

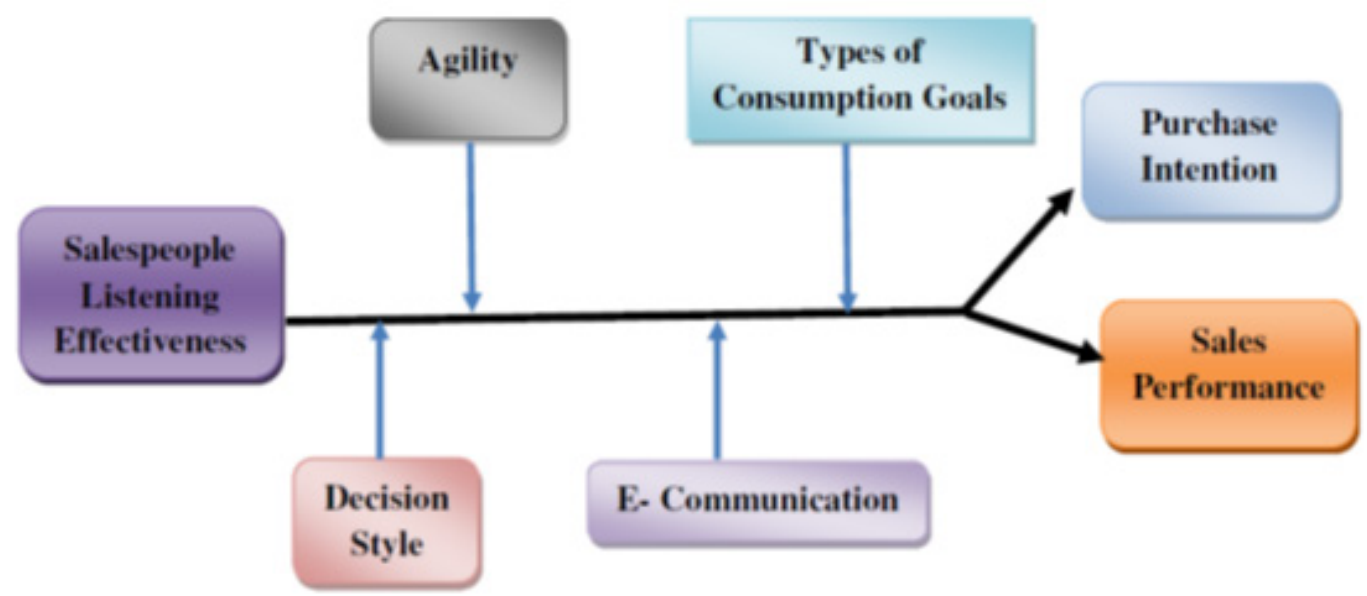

Figure 1 
H2: Salesperson listening effectiveness will increase the organizational sales performance. Agility: Agility has been described as important capabilities for success in a changing business environment [5]. According to Plonka FS [45] agile workforce is consisting of attributes such as attitude toward learning and self-development, problem solving ability, being comfortable with change, new ideas, and new technologies, ability to generate new ideas and accepting new responsibilities. Gunasekaran A [46] identified knowledge in the team working, multifunctional workforce and self-directed teams as the characteristics of agile workforce. Chonko LB, et al. [47] include the agility concept first in the sales literature by considering the fact that an agile workforce is critical to create an agile organization. The basic idea is that sales force will only be agile and will be better able to serve their consumers when the organization itself will attain agility. Workforce agility is imperative condition for salespeople to be agile. Salespeople learn from their organization. If the climate of the organization is such that promotes self-development and knowledge work force as well as change perspective, sales force of that organization will automatically adopt that behavior and start applying that into their daily business practice.

According to Gwinner KP, et al. [48], frontline sales workers should behave in such a way that they serve the each customer in terms of their need and want and also they must be able to understand the customer's concern well, and match their concern with the appropriate service that the firm offers. Another study, Bettencourt [49] states that the frontline sales-people has the opportunity to tailor in real-time not only the sales offers but also the way in which those services are delivered. According to Breu $\mathrm{K}$, et al. [50], agile people are multi-skilled and flexible, they rely less on sales or service system and more rely on the knowledge and opportunity that lead to the better customer relationships [51]. The main characteristic of agile people is that they use their skills, knowledge, judgment, experiences, and attitude to deal with the unknown situation [51]. They are always open to new idea and hence believe in continuous learning process as well as adopt new practices very quickly. According to Attafar A, et al. [52] agile salespeople represents flexibility and adaptability, responsiveness, speed, low complexity, mobilization of core competences and highquality customized products.

Organization's performance is mostly driven by an organization's culture. Harris [2] mention in his current book that organizational culture is the sum of all the many hundreds and thousands of personal interactions between its members where face-to-face conversations, discussions, presentations, debates, and meetings are the building blocks of culture. As Chonko Alb, et al. [47] found that the top management plays an important role to set an ethical tone within the organization, managers also set the standards within the organization through their interactions with others. Harris [2] shows that managers use their "conversations and discussions as tools, not only to better their own performance, but also to lead by example, to demonstrate what they believe to be, or what they wish to be, the acceptable norms and boundaries for behavior and performance". He also mentions that top management of the agile workforce consistently look for new ways and procedures to decision making by seeking more relevant perspectives on an issue and at the same time also encourage employees especially salespeople to tackle new problems in the same way. Having understood the fact that only an agile workforce is capable of creating an environment where listening behavior can take place, therefore, it is reasonable to believe that:

H3: Agility will moderate the relationship between salesperson listening effectiveness and sales performance and purchase intention where the presence of workforce and sales agility will enhance or strengthen this relationship.

Decision style: Decision making style has been defined as "a habitual pattern individuals use in decision making" [53]or individuals' characteristic mode of perceiving and responding to decision-making tasks [54]. Johnson RH [55] describes that individual gather information for decision making purpose either through a systematic or spontaneous manner. Hunt RG, et al. [56] states that "the majority of individuals would be classified as consistently analytic or consistently intuitive in both information gathering and information evaluation". Scott SG, et al. [57] identified four decision styles which are (a) rational decision-making style that consist of through search for and logical evaluation of alternatives, (b) intuitive decision-making style involves reliance on hunches and feelings, (c) dependent decision-making style involve search for advice and direction from others, and (d) avoidance decisionmaking style which involves attempts to avoid decision making. Individuals who employ dependent decision-making style are more likely to seek information from the reliable and knowledgeable sources. In the buying scenario, these people will rely more on salespeople for gathering product information and make their buying decisions. Wilson DT [58] describes that salespeople should emphasize different persuasive arguments depending upon the buyers' decision styles. Salespeople should listen more carefully those consumers who have dependent decision-making styles to understand their specific needs and guide them in an appropriate way by providing necessary information so that they can have pleasurable buying experiences. Hence, more pleasurable buying experience leads to more customer satisfaction and more future interaction with the salespeople and organization. On the otherhand, consumers with intuitive decision-making styles do not always seek assistance from the salespeople and hence salespeople listening effectiveness will be relatively less needed dealing with those consumer group. Sales performance or purchase intention will not be influenced very much by the salespeople listening effectiveness when salespeople deal the consumers with intuitive decision-making style. Therefore, it can be assumed that:

H4: Consumer's decision-making styles moderate this relationship between salesperson listening effectiveness and both purchase intention and sales performance where dependent decision-making style will strengthen the listening effectiveness and intuitive decision-making style decreases the relationship. 
E-communication: Salespeople's orientation to e-communication has some influence on the listening effectiveness and sales performance. Salespeople who are more inclined to ecommunication method will have more listening skills. They listen to their consumers through using the e-communication method in order to serve them in a better and more efficient ways. For example, participating in social media group enables salespeople to gain critical knowledge as it helps targeting and researching about individuals and companies [59]. Moreover, social media outlets enable salespeople to connect with their customers instantaneously, which in turn lead to better customer service, loyalty and retention [59]. In regard to social media use, Lager M [60] found that not all companies can be benefitted by using social media. He mentioned that social media use decision is based on the corporate culture and capabilities. Small businesses are not all that interested in integrated social stuff [60]. A study conducted by Bryant [20] found that most of the salespeople think that e-communication is not as helpful as conventional person-person contact for generating sales. Moreover, Mortimer K [61] found that credence customers depend more on the opinion of salespeople, the experience of friends and the content of consumer reports. They conclude that impersonal independent information can now easily be sourced on the internet and can provide a purchaser with comparisons of the main players and their strengths. Armed with this knowledge the purchaser can have an informed discussion with the salesperson before making the decision. Based on the above analysis, it is reasonable to assume that:

H5: Salespeople orientation to e-communication method will moderate the relationship between salesperson listening effectiveness and both purchase intention and sales performance where using e-communication method will strengthen the relationship and conventional method will weaken the relationship.

Types of consumption goal: Dhar $R$, et al. [62]state that consumer choices are driven by utilitarian and hedonic considerations. Chitturi $\mathrm{R}$ [63] defined utilitarian benefits as a functional, instrumental, and practical benefits of consumption offerings whereas hedonic benefits as an aesthetic, experiential, and enjoyment-related benefits. They analyze these benefits in the context of cell phones and categorize phone's battery life and sound volumes are as utilitarian benefits, whereas aesthetic appeal from its shape and color are as hedonic benefits. Chernev A [13] shows that the types of goals consumers expect to be fulfilled by the utilitarian dimension of a product are different from those they seek from the hedonic dimension [63]. Specifically, consumers tend to fulfill the prevention goals through the utilitarian dimensions of the products whereas they tend to fulfill the promotion goals through the hedonic dimension of the product $[63,13]$. According to the regulatory focus theory $[33,34]$, "prevention goals are those that ought to be met, such as behaving in a safe and secure manner and being responsible [63]. For example, in the case of a car, prevention goals might be served by its safety features or the tenyear or 100,000-miles bumper-to bumper warranty that the car manufacturer offers. Conversely, "promotion goals are those that a person aspires to meet, such as looking cool or being sophisticated" [63].

According to Chitturi R, et al. [16] consumers give more importance to the hedonic (versus utilitarian) dimension, but only after when consumers found that the product's baseline functionality is met [63]. Similarly, Kivetz R, et al. [37] document that consumers attach greater weight to the utilitarian dimension than hedonic dimension, unless they believe that they have "earned the right to indulge" [63]. Sales-people listening skills play an important role during the consumption choice scenario. According to Ferrari TF [20], effective listening allows someone to formulate the right questions and generate the necessary interjections and interruptions to advance the conversation productively. Hence, effective listening skills allow salespeople to think further based on the conversation with their consumer and try to figure out whether or not consumer's utilitarian dimensions have been met. SaloveyP, et al. [64] document emotional intelligence which is as a subset of social intelligence and the "ability to monitor one's own and others' feelings and emotions, to discriminate among them and use this information to guide one's thinking and actions". Further, possessing emotional intelligence indicates that an individual is able to regulate theirs and other emotions and use feelings to "motivate, plan, and achieve in one's life". Active-empathic listening skills allow salespeople to show their emotional involvement in the process and hence inspire consumers to purchase more hedonic products that are more emotional oriented consumption by letting them know how they have earned the right to indulge and how this behavior is justified. Here salespeople will act as real third-party consultants on behalf of the consumers who wish to buy hedonic products. Therefore, the above discussion lead to the following hypothesis:

H6: Types of consumption goal moderates the relationship between the salespeople listening effectiveness and both purchase intention and sales performance where hedonic consumption goal strengthen the relationship whereas utilitarian consumption goal weaken the relationship.

\section{Proposed Research Design and Methodology}

\section{Industry selection}

There are very few empirical studies available in the context of salespeople listening effectiveness and its relationship to other long-term variables such as purchase intention, sales performance, trust, satisfaction, word-of-mouth so on. While most of the investigation that analyzed consequences of effective listening in buyer-seller relationships have been conducted in the product market, Bergeron J, et al. [9] is one of the papers that studies those relationship in the context of service industry. Following the methodology proposed in Bergeron J, et al. [9] paper, I would also like to select retail banking industry because salespeople often participate in lengthy conversations with customers and must rely on their communication skills to gather information, analyze customer needs and provide relevant solutions Bergeron J, et al. [9]. For example, one of the biggest financial company in Singapore 
has a slogan that is "always listening, always understanding," which represents a prime example of a people-oriented industry that rely heavily on effective listening skills for relationship continuity $[29,2]$.

\section{Sampling Procedures and data collection}

In order to empirically test our model, this study requires a number of possible participants, ranging from the experienced senior financial advisor (salespeople) to the young college student (customer). Ramsey RP, et al. [7] reported that it is important to look at customers' perception of salespeople's listening behavior; buyer-seller dyadic relationship will be investigated in this paper. Therefore, data will be collected both from salespeople and customer. Two self-administered questionnaires will be developed - one for salespeople and other one for customers. Following the sampling procedure used by Bergeron J [26], customers will be asked to recall the meeting, they just had with their salespeople and then asked to answer those several questions in order to measure our construct [26].

\section{Measures}

The measures in this study will be adapted from previous research. Wording of the measures will be modified to suit the context of the study where appropriate.

Salespeople listening: Salespeople listening will be assessed using a 13-item scale developed by Ramsey RP, et al. [7]. The scale reflects the construct of salespeople listening as sensing, evaluating and responding.

Purchase intention: Purchase intention will be measured using four questions adapted from Crosby et al. that assess the customer's desire to conduct future business with the salespeople. Moreover, two additional questionnaires will be added following the Verret [30] whether or not customer would be likely to refer this salespeople to another person in the future (using 7-point likert scale) and 2) an open ended question asking customer to briefly explain why or why not they would continue doing business with the salespeople [30].

Sales performance: Following Evans KR, et al. [26] paper, 6-items scale (for instance, "contributing to your company's acquiring a good market shares") will be used to measure salesperson outcome performance. Finally, according to Jaramillo et al. [48] social desirability bias will be measured with 4-items reported in Donavan et al. [13].

Agility: Jaramillo [48] has evaluated agility with 9-items (for instance, I view changes in customer preferences as an opportunity rather than a threat) based on [18] conceptualization.

Decision-making style: Scott SG, et al. [52] measure of decision-making style will be used to measure dependent and intuitive decision-making style.

E-communication: Parasuraman A [45] developed a technology readiness index (TRI) multiple item scale that companies can use to gain an in-depth understanding of the readiness of their employees and customers (both external and internal) to embrace and interact with technology, especially computer/Internet-based technology. TRI scale will be used in this paper to measure the e-communication method of the salespeople.

\section{Potential Implications (Managerial and Research)}

This study offers several managerial implications. First of all, mangers need to know the importance of listening behavior and how this behavior can transform the business practice. Having understood that there is a positive relationship between salespeople listening effectiveness and sales performance and purchase intention, managers should consider listening abilities a high priority quality into their recruitment and selection procedure. Listening concept should be incorporate in the strategic business planning. Also, management should assess the need for ongoing listening training courses with auto-evaluations, interviews, employees'

feedback, and so on [9]. Furthermore, management should develop a listening tracking system to monitor salespeople listening performance as well as effective client knowledge database also need to be developed and exploited [9]. This paper potentially guides future researcher to do more research on the variables that influence salespeople perceived listening skills. Future research can also examine how salespeople listening effectiveness is affected by the presence of others. It would be also worthwhile to study the differences in gender and listening style preferences.

\section{Conclusion}

The main objective of this paper is the reexamine the direct relationship of few key variables in relation to salespeople listening effectiveness at the presence of some new moderating variables. It is expected that the result will empirically show that listening effectiveness is positively associated with sales performance and purchase intention. Hence, this result will support the "implied common-sense role that listening plays in the enactment, development, and maintenance in an array of buyerseller relationships" [9]. Finally, this paper will help salespeople by showing that customers highly value the salespeople listening skills and it can be one of the strategic tools to increase their sales and performance level. Listening effectiveness can improve the relationship marketing concept and hence the knowledge that perceived listening effectiveness can affect customer relationships, is valuable for both sales force managers and salespeople [9].

\section{Acknowledgement}

None.

\section{Conflict of Interest}

Authors declare no conflict of interest.

\section{References}

1. Attafar A, Ghandehari M, Momeni G (2012) Study of Required Organizational Base for Implementation of Agility Strategy in Organizations (Case Study: Industrial Entekhab Group). Interdisciplinary Journal of Contemporary Research in Business 3(11): 1-10. 
2. Harris, Richard MH (2006) The Listening Leader - Powerful New Strategies for Becoming an Influential Communicator. Westport, Connecticut London.

3. Wolvin AD, Coakley CG (1992) Listening / Andrew Wolvin, Carolyn Gwynn Coakley, ( $5^{\text {th }}$ edn), Madison : Brown \& Benchmark, USA, p. 423.

4. Chandon JL, Leo PY, Philippe J (1997) Service encounter dimensions-a dyadic perspective: Measuring the dimensions of service encounters as perceived by customers and personnel. International Journal of Service Industry Management 8(1): 65-86.

5. Menor JM, Roth AV, Mason CH (2001) Agility in Retail Banking: A Numerical Taxonomy of Strategic Service Groups. Manufacturing \& Service Operations Management 3(4): 273.

6. Swan JW, Oliver RL (1991) An Applied Analysis of Buyer Equity Perceptions and Satisfaction with Automobile Salespeople. Journal of Personal Selling \& Sales Management 11(2): 15-26.

7. Ramsey RP, Sohi RS (1997) Listening to Your Customers: The Impact of Perceived Salesperson Listening Behavior on Relationship Outcomes. Journal of the Academy of Marketing Science 25(2): 127-137.

8. Jo Bitner M, Booms BH, Tetreault MS (1990) The Service Encounter: Diagnosing Favorable and Unfavorable Incidents. Journal of Marketing 54(1): 71- 84 .

9. Bergeron J, Laroche M (2009) The effect of perceived salesperson listening effectiveness in the financial industry. Journal of Financial Services Marketing 14(1): 6-25.

10. Moore JR, Eckrich DW, Carlson LT (1986) A hierarchy of industrial selling competencies. Journal of Marketing Education : 79-99.

11. Saxe R, Weitz BA (1982) The SOCO scale: A measure of the customer orientation of salespeople. Journal of Marketing Research 19(3): 343351.

12. Salovey P, Mayer JD (1990) Emotional intelligence. Imagination, Cognition and Personality 9(3): 185-211.

13. Donald WC, Danny LW (1991) Twelve rewards of becoming a powerful listener. Agency Sales Magazine 21(2): 29-31.

14. Stephen RC (1987) The seven habits of highly effective people. New-York Simon \& Schuster, USA.

15. Dion PA, Notarantonio EM (1992) Salesperson communication style: The neglected dimension in sales performance. Journal of Business Communication 29(1): 63-77.

16. Peter FD (1993) Mananging in turbulent times New York, NY: Harper \& Row.

17. Peter T, Austin N (1985) A passion for excellence. New-York: Random House, USA.

18. Bergeron J (2004) Antecendents and consequences of salesperson listening effectiveness in buyer-seller relationships. ProQuest Dissertations and Theses, ProQuest.

19. Castleberry SB, Shepherd CD (1993) Effective interpersonal listening and personal selling. Journal of Personal Selling and Sales Management 13(1): 35-40.

20. Bernard TF (2012) Power Listening - Mastering the Most Critical Business Skill of All. Portfolio/ Penguin, New York, USA.

21. Donald WC, Danny LW (1991) Twelve rewards of becoming a powerful listener. Agency Sales Magazine 21(2): 29-31.

22. Jo Bitner M, Booms BH, Mohr LA (1994) Critical Service Encounters: The Employee's Viewpoint. Journal of Marketing 58(4): 95-106.

23. Micheal LB (1994) Involved listening as a salesperson skill variable and its impact upon adaptive selling and sales performance. Doctoral Dissertation, University of South Florida, USA.

24. Wall Street Journal (1990) Talk, talk, talk, talk: Try a little listening. 22(March): pp. B1.

25. Frederick E, Webster Jr (1968) Interpersonal communication and salesperson effectiveness. Journal of Marketing 32: 7-13.
26. Bergeron J (2004) Antecendents and consequences of salesperson listening effectiveness in buyer-seller relationships. ProQuest Dissertations and Theses, ProQuest.

27. Lucette BC, Tanya D, Jing D (1999) Three faces of empathy: A new look at an old continuum. In Michael A. Humphreys (Edt), National Conference in Sales Management Proceedings: 105-116.

28. Miller, Joseph C (2010) Service agility: A crucial component of service strategy. Michigan State University, USA.

29. Boshoff C, Allen J (2000) The influence of selected antecedents on frontline staff's perceptions of service recovery performance. International Journal of Service Industry Management 11(1): 63 - 90.

30. Verret, Megan J (2000) The impact of buyer/seller listening styles on mutual trust, satisfaction, and anticipation of future interactions. ProQuest Dissertations and Theses, ProQuest.

31. Richard TE (1990) You cannot communicate unless you are a good listener. American Salesman 35(10): 28-29.

32. Micheal LB (1994) Involved listening as a salesperson skill variable and its impact upon adaptive selling and sales performance. Doctoral Dissertation, University of South Florida, USA.

33. Weitz BA, Sujan H, Sujan M (1986) Knowledge, motivation, and adaptive behavior: A framework for improving selling effectiveness. Journal of Marketing 50(4): 161-173.

34. Thomas RW, Soutar GN, Ryan MM (2001) The Selling OrientationCustomer Orientation (SOCO) Scale: A Proposed Short Form. Journal of Personal Selling \& Sales Management 21(1): 63-69.

35. Bergeron J, Laroche M (2009) The effect of perceived salesperson listening effectiveness in the financial industry. Journal of Financial Services Marketing 14(1): 6-25.

36. Nugent WR (1992) The affective impact of a clinical social worker's interviewing style: A series of single case experiments. Research on Social Work Practice 2(1): 6-27.

37. Luce MF (1998) Choosing to avoid: Coping with negatively emotionladen customer decisions. Journal of Consumer Research 24(4): 409424.

38. Morey S (1988) Salespeople who listen. Management Review 77: 44-45.

39. Chernev A (2004) Goal-Attribute Compatibility in Consumer Choice. Journal of Consumer Psychology 14(1-2): 141-150.

40. Wolvin AD, Coakley CG (1996) Listening. Dubuque, IA: Brown \& Benchmark, USA.

41. Shepherd CD, Castleberry SB, Ridnour RE (1997) Linking effective listening with salesperson performance: An exploratory investigation. Journal of Business and Industrial Marketing 12(5): 315-322.

42. Boorom ML, Goolsby JR, Ramsey RP (1998) Relational communication traits and their effect on adaptiveness and sales performance. Journal of the Academy of Marketing 26: 16.

43. Spiro RL, Weitz BA (1990) Adaptive selling: Conceptualization measurement, and nomological validity. Journal of Marketing Research 27(1): 61-69.

44. Castleberry SB, Shepherd CD, Ridnour R (1999) Effective interpersonal listening in the personal selling environment: Conceptualization, measurement, and nomological validity. Journal of Marketing Theory and Practice 7(1): 30-38.

45. Plonka FS (1997) Developing a lean and agile workforce. Human Factors and Ergonomics in Manufacturing \& Service Industries 7(1): 11-20.

46. Gunasekaran A (1999) Agile manufacturing: a framework for research and development. International Journal of Production Economics 62(12): 78-105.

47. Chonko LB, Hunt SD (1985) Ethics and Marketing Management: An Empirical Examination. Journal of Business Research 13(4): 339-359.

48. Gwinner KP, Jo Bitner M, Brown SW, Kumar A (2005) Service Customization Through Employee Adaptiveness. Journal of Service Research 8(2): 131-48. 
49. Wolvin AD, Coakley CG (1996) Listening. Dubuque, IA: Brown \& Benchmark, USA.

50. Breu K, Hemingway CJ, Strathern M, Bridger D (2002) Workforce agility: the new employee strategy for the knowledge economy. Journal of Information Technology 17(1): 21-31.

51. Chonko LB, Jones CE (2005) The Need for Speed: Agility Selling. The Journal of Personal Selling and Sales Management 25(4): 371-382.

52. Attafar A, Ghandehari M, Momeni G (2012) Study of Required Organizational Base for Implementation of Agility Strategy in Organizations (Case Study: Industrial Entekhab Group). Interdisciplinary Journal of Contemporary Research in Business 3(11): 1-10.

53. Driver MJ(1979) Individual decision making and creativity. Kerr S (Edt), Organizational behavior, Columbus, OH: Grid Publishing, USA.

54. Harren VA (1979) A model of career decision making for college students. Journal of Vocational Behavior 14(2): 119-133.

55. Johnson RH (1978) Individual Styles of Decision Making: A Theoretical Model for Counseling. The Personnel and Guidance Journal 56(9): 530536.

56. Hunt RG, Krzystofiak FJ, Meindl JR, Yousry AM (1989) Cognitive style and decision making. Organizational Behavior and Human Decision Processes 44(3): 436-453.
57. Scott SG, Bruce RA (1995) Decision-making style: The development and assessment of a new measure. Educational and psychological measurement 55(5): 818-831.

58. Wilson DT (1971) Industrial buyers' decision-making styles. Journal of Marketing Research 8(4): 433-436.

59. Joe R (2012) Use Social Media to Help Build More Sales. Sales Clinic.

60. Lager M (2009) No One’s Social Yet. Sales and Social Media.

61. Mortimer K, Pressey A (2013) Consumer information search and credence services: implications for service providers. Journal of Services Marketing 27(1): 49-58.

62. Dhar R, Wertenbroch K (2000) Consumer Choice Between Hedonic and Utilitarian Goods. Journal of Marketing Research 37(1): 60-71.

63. Chitturi R, Raghunathan R, Mahajan V (2008) Delight by design: the role of hedonic versus utilitarian benefits. Journal of Marketing 72(3): 48-63.

64. Salovey P, Mayer JD (1990) Emotional intelligence. Imagination, Cognition and Personality 9(3): 185-211. 